\title{
HYDRODYNAMICS IN SPRAY AND PACKED LIQUID-LIQUID EXTRACTION COLUMNS: A REVIEW
}

\author{
Milan N. Sovilj ${ }^{1}$, Branislava G. Nikolovskii ${ }^{1}$, Momčilo Đ. Spasojević \\ ${ }^{1}$ Faculty of Technology, University of Novi Sad, 21000 Novi Sad, Serbia \\ ${ }^{2}$ Faculty of Technical Sciences, University of Novi Sad, 21000 Novi Sad, Serbia \\ miso@uns.ac.rs
}

This work provides a review of hydrodynamic characteristics such as the slip velocity, the dispersed-phase holdup, mean drop size, and axial dispersion of non-mechanically agitated liquid-liquid (LL) extractors, with special reference to spray and packed bed columns. The complexity and importance of hydrodynamic behavior in designing and scaling up L-L extractors was a driving force to analyze, compare and discuss some important experimental findings available in the literature. The effects of phase velocities and the dispersed-phase holdup on the slip velocity, the mean drop size and the axial dispersion coefficient were studied and presented. Empirical correlations for slip velocity, the Sauter mean drop diameter and the axial dispersion coefficient, which were taken from the literature, were commented in terms of their applicability.

Keywords: spray and packed bed columns; slip velocity; dispersed-phase holdup;

Sauter mean drop diameter; axial dispersion coefficient

\section{ХИДРОДИНАМИКА НА ТЕЧНО-ТЕЧНИ ЕКСТРАКЦИОНИ КОЛОНИ СО РАСПРСНУВАњЕ И СО ПАКУВАНО ПОЛНЕЊЕ: ПРЕГЛЕД}

Во овој труд е направен преглед на хидродинамичките карактеристики како што се привидната брзина на фазите, содржината на дисперзираната фаза, средниот пречник на капките, како и аксијалните дисперзиони коефициенти во однос на колони со распрснување и пакувано полнење. Комплексноста и важноста на хидродинамичкото однесување при дизајнирање и димензионирање на L-L-екстракторите беше главен мотив за анализа, споредба и дискусија на некои важни експериментални податоци од литературата. Направена е студија и извршена е презентација на влијанието на брзината на континуираната и дисперзираната фаза, средниот пречник на капките и аксијалниот дизперзионен коефициент. Тие се коментирани во однос на нивната применливост, емпириските корелации што се однесуваат на привидната брзина на фазите, средниот пречник на капките според Sauter и аксијалниот дисперзионен коефициент преземен од литературата.

Клучни зборови: колони со распрснување и пакувано полнење; привидна брзина на фазите; содржина на дисперзирана фаза; среден пречник на капки според Sauter; аксијален дисперзионен коефициент

\section{INTRODUCTION}

Liquid-liquid extraction is a well-known separation process which has been widely used in process industries for many years. In this process, a solute is transferred between the drops of the dispersed phase and the bulk of the immiscible continuous phase [1, 2]. Studying the steady-state movement of drops within the liquid phase is recommended by researchers to obtain a theoretical 
basis for liquid-liquid extraction systems. The spray column is the simplest column among liquidliquid (L-L) extraction columns. Packed columns are similar in principle to spray columns, but they are more efficient because packing elements serve to decrease axial mixing, reduce back-mixing of the continuous phase, provide tortuous pathways for the two liquids, and can also cause distortions and breakup the drops. As a result, mass transfer can be further improved [3]. Because of their simplicity, the spray and packed column are frequently used instead of other extraction columns in the research of drop behavior mass transfer ratio, etc. [4, 5]. One of the most important characteristics of liquid extraction columns is the dispersed-phase drop behavior, due to its effect on the mass transfer coefficient $[6,7]$. While a large number of papers exist in the literature concerning the prediction of the drop size distribution in liquid-liquid dispersions in extraction columns, most of them are only applicable to particular conditions of these processes [8]. Relative simplicity, speed and a wide scope of solvent extraction processes contribute to their numerous applications in various industrially important fields. Mass transfer efficiency and capacity in liquid-liquid contactors depend not only on the chemical systems and their physical properties, but also on many other factors, some of which are the amount of the solvent present in the extractor, the mass transfer direction and the drops' path length and velocity [3, 6-8].

The complexity and importance of hydrodynamic behavior in designing and scaling up L-L extractors was a driving force to analyze, compare and discuss some important experimental findings available in the literature. For the design and scaleup of L-L extractors, knowledge of hydrodynamic parameters such as the slip velocity between the phases, the mean drop size, the dispersed-phase holdup, the axial dispersion coefficient, and the mass transfer coefficient is necessary $[8,9]$.

\section{THEORY}

\subsection{The basics of the liquid-liquid extraction process and design}

In the extraction process, the liquid feed mixture is brought into close contact with the second liquid solvent phase, referred to as the extraction solvent, in which the feed's components can be partitioned to different extents. The selected solvent should be nearly immiscible with the liquid feed mixture and should selectively dissolve the feed's components, preferably only the desired components of the liquid feed mixture. During the extraction process, the drops of the dispersed phase accumulate below or above the continuous phase and the boundary between the continuous phase and the drop dispersion is called the interface. Rapid coalescence in the extrication system is related to high interfacial tension, and slow coalescence rates are attributed to low interfacial tension [1]. The potential for separating the feed components is determined by the differences in this interaction. The mass transfer rate between two liquid phases can be calculated by multiplying the driving force applied, the mass transfer area and the mass transfer coefficient $[1,3]$.

The basis for the design of the liquid-liquid extraction process in many cases is to conduct laboratory studies on solvent extraction (shake tests under realistic conditions) which provide necessary experimental equilibrium data. In order to design L-L extractors, to predict a useful feed-solvent ratio with the required number of theoretical stages and the resulting internal hydraulic tower traffic, proprietary methods and the commercially available process simulation software can use. [3]. At the same time, the design of an extraction column that is very often based on pilot plant data and design experience reviews is far from optimum[3]. Namely, if the amount of the solvent is high compared to the feed, the solute mass transfer is favored [4]. When the solute is transferred to the dispersed organic phase, an increase in efficiency may be observed compared with the opposite direction of transfer, although this transfer direction can also result in decreased throughput capacity $[5,6]$. The effects of drop deformation, oscillations on the mass transfer rate, and the phenomena of the Marangoni convection in liquid-liquid systems have been extensively studied in the literature [7]. However, a wide drop size distribution in a turbulent flow is considered to be one of the main problems in designing L-L extractors [7]. Such polydispersity, which can occur in L-L extraction systems, together with wall bypassing, channeling, and large scale circulations at the phase inlet, causes different or varying drop velocities [8-10].

\subsection{Spray and packed bed columns}

Numerous extractors have been described in the literature [7-12]. The continuous operation is carried out in spray and packed columns, both of which are non-mechanically agitated, i.e. static, plate columns. Pratt and Stevens [6] summarized the characteristics of the most important types of industrially relevant extractors, and also discussed the selection, design and scale-up of the equipment. Some of the simplest designs in L-L extrac- 
tion are spray columns without internal elements and packed columns containing randomly filled and stacked packing elements, tube columns or columns with structured packing [6]. Spray columns and packed bed columns are the most important and vastly studied extractors with the gravity force as a separation factor.

The spray extraction column represents a limiting case of the packed column and because of its simple nature has been investigated extensively in the laboratory [6]. A number of studies by Hughmark [13], Letan and Kehat [14], and Steiner and Hartland [15], have investigated the hydrodynamic characteristics of the spray column. Generally, the spray column extractor efficiency is quite low due to problems that are inherent to a low interfacial area of liquid phases, the lack of dispersion-coalescence cycles inside the extractor, and substantial back-mixing in the continuous phase. It has been shown that back-mixing is reduced when the spray column operates with the dense packing of drops and high dispersed-phase holdups. The other way to increase the efficiency of the spray column is to introduce an inert gas phase (oxygen, nitrogen, air) in the two-phase L-L system [16]. This method of energy introduction increases the turbulence within the three-phase gas-liquid-liquid (G-L-L) system, which causes the improved dispersion of drops, a higher dispersed-phase holdup and consequently a greater mass transfer area. Different empirical relations have appeared in the literature that describe functions of slip velocity, the dispersed-phase holdup, the gas-phase holdup, the axial dispersion coefficient, and the mass transfer coefficient in G-L-L systems [17-19].

While the spray column cannot compete with the sophisticated and efficient extractors now used in industry, its advantages lie in its simplicity, low operation costs, and insensitivity to impurities [20]. The spray column extractor is a good choice when fluids contain high quantities of suspended solids. Moreover, it provides a suitable standard for checking hypothetical models and theoretical principles, which then may be extended to other extractor types by respecting additional influences [21]. The difficulties in scaling up extractors are caused by the complexity of internal flows that are usually far from ideal and more difficult to predict than mass transfer phenomena themselves. It is assumed that if the internal flows are properly marked, the descriptions of mass transfer rates may be reduced to several standard situations which are connected to the formation and movement of drops, films, and jets [22-24].

The packed bed extraction column is filled with different packings, random or orde- $\mathrm{red} / \mathrm{structured}$, which causes greater values of mass transfer coefficients and a higher efficiency compared to the spray tower. In practice, the packed column can be operated with Raschig rings, Berl saddles, Pall rings (ceramic or metal), Intalox saddles, corrugated sheet metal and corrugated metal gauze, Flexipac structured packing, Sulzer structured packing [25], and some other new packings such as Nutter rings [8]. The packing increases the drops' path, i.e. the flow path length, consequently increasing residence time for the drop phase and the dispersed-phase holdup. At the same time, it decreases the axial component of the drop velocity, thus reducing the axial back-mixing of the continuous phase caused predominately by the drag effect of the drops $[6,24,25]$. The packing reduces the available free space for flow but also significantly reduces the height required for mass transfer [25]. On the other hand, packed columns are an important unit of industrial equipment, especially in the petrochemical industry. The dispersed-phase holdup is related the pressure loss and is a characteristic parameter of the operated column. It influences the heat and mass transfer in the column [24-26]. There is very little information in the published literature on the packed column with gas agitation. Because the extraction efficiency of the packed column is higher than that of the unpacked column, it is expected that the combination of packing and gas agitation can greatly enhance the L-L contact and mass transfer in the extraction.

In some cases, spray and packed bed extraction columns have been studied simultaneously [5, 6, 24-26]. According to the findings of Appel and Elgin [26], the spray column may be either more or less effective than the packed column operated under the same conditions. Appel and Elgin [26] also concluded that the dispersed-phase flow rate had a greater influence on the capacity of the packed column (1.27 cm Berl saddles) than on the continuous-phase flow rate. Seibert and Fair [11] investigated and discussed the mass transfer efficiencies and hydrodynamic characteristics of packed extraction columns filled with five different packings and the spray column. The performance of these packings was compared with results obtained in the spray extraction column. Maćkowiak [12] analyzed and confirmed several previously published observations of other authors, like Sherwood et al. [6]. In particular, Sherwood et al. studied $1.27 \mathrm{~cm}$ and $2.54 \mathrm{~cm}$ carbon Raschig rings as well as 1.27 $\mathrm{cm}$ ceramic Perl saddles in comparison with the spray column operated under the same conditions. They observed that the packed column was significantly more efficient than the spray column. Sherwood et al. [6] also concluded that packing had a 
negligible effect on the mass transfer coefficient but was effective, in addition to the available interfacial area. Seibert and Fair [11] emphasized that packings improved mass transfer by $2-3$ times in comparison with mass transfer in the spray column. Seibert and Fair's [11] study also confirmed that the drop diameter was a very minor function of the flow rates and packing types. However, according to Seibert and Fair [11] high-efficiency packings gave greater combined capacities and mass transfer efficiencies than traditional random packings. Additionally, in high interfacial tension systems, metal Intalox saddle packing promoted the faster breakup of drops. Salimi-Khorshidi et al. [27] determined a value of the mass transfer coefficient of the packed column $(1 \mathrm{~cm}$ stainless steel Raschig rings) which was about $25 \%$ greater than that of the spray column under similar conditions for the toluene-acetone-water system. The interfacial area and velocity of the phases for mass transfer are higher for the packed column, because, at the same flow rates of the dispersed and continuous phases for both columns, the Sauter mean drop diameter is smaller for the packed column in comparison with that of the spray column [27].

\section{LITERATURE SURVEY OF HYDRODYNAMIC CHARACTERISTICS}

The hydrodynamic characteristics of a system represent one of the main difficulties in the scale-up of L-L extractors [28]. As for the design, difficulties occur mainly due to the dispersion in radial and axial directions; however, in most cases, radial dispersion has a small influence. Extractor equipment without mechanical agitation, such as spray or packed columns, has a high level of performance despite a small interfacial area in both phases because of relatively large drop sizes [29].

The main hydrodynamic characteristics in the non-agitated extraction column are the slip velocity between the phases, the dispersed-phase holdup, the continuous-phase holdup, the drop size distribution, and the continuous-phase axial dispersion coefficient. The drop size distribution plays a key role in liquid extraction systems and accompanying hydrodynamic and mass transfer characteristics [30]. Prediction of liquid dispersion is essential for the optimization of liquid-liquid extraction columns' design. Dispersion of liquid will depend on the selected liquid distributor type and design (number and size of nozzles), and the packed beds' height. However, the results of laboratory experiments focused on liquid dispersion phenomena cannot be directly extrapolated because a laboratory column diameter and height values are at least one order of magnitude lower than the corresponding geometric characteristics of an industrial column $[31,32]$. Thus, it is necessary to rely on industrial feedback or to eventually use computational fluid dynamics simulation tools.

The following section reviews the effects of hydrodynamic characteristics on the operation in some non-mechanically agitated L-L extraction columns.

\subsection{Slip velocity and dispersed-phase holdup}

Mass transfer between the liquid phases in a non-mechanically agitated extraction column depends on its operating conditions and geometry that determine flowrates and patterns, the physical characteristics of solvents and the solute concentrations. At the same time, the most important characteristic is the contact interfacial area between the continuous and the dispersed phase. The contact interfacial area for mass transfer depends on the dispersed-phase holdup, the rate of drop formation and the average surface area per drop, which can be calculated if the mean drop size is known. It is therefore important, at the design stage, to be able to predict the dispersed-phase holdup [6, 32-35].

Sovilj et al. [32] investigated the hydrodynamic characteristics of liquid-liquid system toluene-water in a pilot plant extraction column $(D=10$ $\mathrm{cm}, L=273.5 \mathrm{~cm}, d_{\mathrm{N}}=0.15$ or $\left.0.20 \mathrm{~cm}\right)$. The effect of the dispersed-phase holdup on the ratio of dispersed-phase superficial velocity and characteristic velocity is presented in Figure 1.

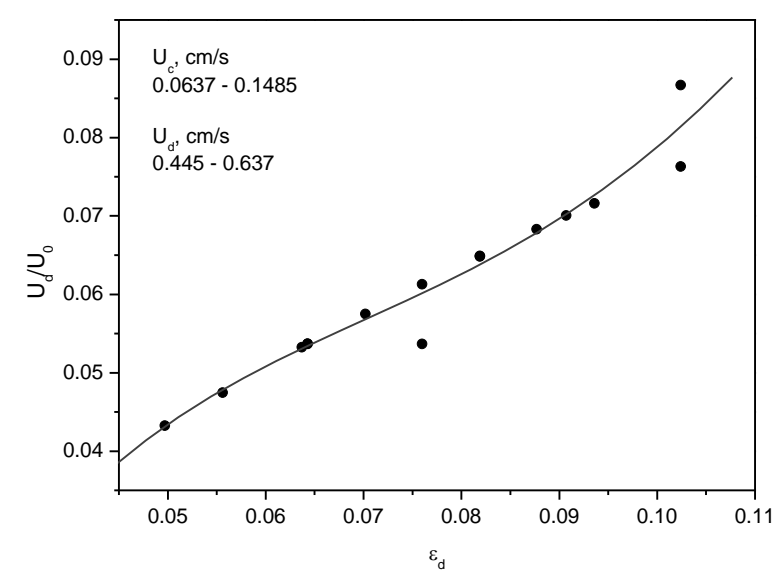

Fig.1. Effect of the dispersed-phase holdup $\left(\varepsilon_{d}\right)$ on the ratio of dispersed-phase velocity and characteristic velocity $\left(\mathrm{U}_{\mathrm{d}} / \mathrm{U}_{0}\right), d_{\mathrm{N}}=0.15 \mathrm{~cm}$ (Source: Sovilj et al. [32])

Figure 1 shows that the ratio $U_{d} / U_{0}$ tended to increase when the dispersed-phase holdup $\left(\varepsilon_{d}\right)$ was increased. From Figure 1 it can be also concluded 
that the dispersed phase holdup characteristic of the flooding point was not achieved for the flow conditions used.

At the flooding point, flow rate(s) of the phase(s) increase to the extent that a second interface at the opposite end of the column to the main interface appears. In order to understand the principles behind flooding and to predict it, the slip velocity between the phases and the characteristic velocity are defined. In the spray L-L extraction column, the basic hydrodynamic characteristics for the counter-current flow are connected by the relationship of Godfrey and Slater [36]:

$$
U_{s}=\frac{U_{d}}{\varepsilon_{d}}+\frac{U_{c}}{\left(1-\varepsilon_{d}\right)}
$$

There have been many attempts to relate the slip velocity to the holdup. The dispersed-phase holdup for spray columns can be related to the phase flow rates by the following relation, derived originally for packed columns, and applied subsequently to pulsed and rotary annular columns [36]:

$$
\frac{U_{d}}{\varepsilon_{d}}+\frac{U_{c}}{\left(1-\varepsilon_{d}\right)}=k U_{0}\left(1-\varepsilon_{d}\right)
$$

where $k$ is the constant.

A plot of $\left[U_{\mathrm{d}}+U_{\mathrm{c}} \varepsilon_{\mathrm{d}} /\left(1-\varepsilon_{\mathrm{d}}\right)\right]$ vs. $\varepsilon_{\mathrm{d}}\left(1-\varepsilon_{\mathrm{d}}\right)$ is linear with a slope of $k U_{0}$ and enables the characteristic velocity to be determined from the flow rate and holdup measurements. In the case of spray columns, it is possible to predict $U_{0}$ on the basis of the normal correlation of the free-falling velocity for spheres, assuming the drop size to be given by Hayworth and Treybal's relationship [37].

Varfolomeev et al. [38] corrected Eq. (1) by the addition of a new part, as follows:

$$
\frac{U_{d}}{\varepsilon_{d}}+\frac{U_{c}}{\left(1-\varepsilon_{d}\right)}=U_{0}\left(1-\varepsilon_{d}\right)^{m}
$$

where $m$ is defined by:

$$
m=1.22\left(\frac{\mu_{d}}{\mu_{c}}\right)^{2}
$$

If the static dispersed-phase holdup is defined as $\mathcal{E}_{s t}=U_{d} / U_{s}$, when $U_{c}=0, E q$. (1) can be rewritten in the form:

$$
U_{\mathrm{s}}=\frac{U_{d}}{\varepsilon_{s t}}=\frac{U_{d}}{\varepsilon_{d}}+\frac{U_{c}}{\left(1-\varepsilon_{d}\right)}
$$

On the other hand, the slip velocity is a function of the drop size, physical properties of the L-L system and the dispersed-phase holdup. Pilhofer [39] developed the following equation to correlate the slip velocity in the spray L-L extraction column:

$$
\frac{U_{s} d \rho_{c}}{\mu_{c}}=\frac{3 w q^{2} \varepsilon_{d}}{\left[\left(1-\varepsilon_{d}\right) q^{3} C_{1}\right]}\left\{\left[\frac{c_{1} q^{3} A r\left(1-\varepsilon_{d}\right)^{3}}{54\left(w q^{2} \varepsilon_{d}\right)^{2}+1}\right]^{0.5}-1\right\}
$$

where $\mathrm{C}_{l}$ is the constant. On the basis of the analysis of 591 data points for 16 systems from 8 different sources, Kumar et al. [40] presented a simple model for the prediction of the holdup and slip velocity in spray columns in which the continuous phase moves counter-current to the dispersed phase:

$$
\frac{U_{s}^{2}}{d g}=2.725\left(\frac{\Delta \rho}{\rho_{c}}\right)\left(\frac{1-\varepsilon_{d}}{1+\varepsilon_{d}^{1 / 3}}\right)^{1.834}
$$

This equation is valid for $7<\operatorname{Re}<2,450$ and $0.01<\mathcal{E}_{\mathrm{d}}<0.75$. The equation predicts the slip velocity to within $10 \%$ for $70 \%$ of the data points and to within $20 \%$ for $92 \%$ of the data points. Eq. (7) gives the average absolute relative deviation (AARD) of $13.5 \%$ and $14.5 \%$ for the slip velocity and dispersed-phase holdup, respectively [40]. Kumar and Hartland [41] developed an empirical expression for the prediction of the dispersedphase holdup and slip velocity in drop dispersions settling under gravity. The analysis of 998 published experimental results for 29 liquid-liquid systems from 14 different data sources shows that the slip velocity of the drop swarm is given in terms of the drop diameter and physical properties of the system by:

$$
\frac{4 d g \Delta \rho\left(1-\varepsilon_{d}\right)}{3 \rho_{c} U_{S}^{2}\left(1+4.56 \varepsilon_{d}^{0.73}\right)}=0.53+\frac{24 \mu_{c}}{U_{s} d \rho_{c}}
$$

Good agreement between the experimental and predicted values of the slip velocity was obtained over a wide range of holdups (0.01 to 0.76) and Reynolds numbers (0.16 to 3,169).

Seibert and Fair [11] investigated the results of mass transfer efficiencies and hydrodynamic characteristics of a $10.24 \mathrm{~cm}$ i.d. packed extraction column. The glass extraction column had a $170 \mathrm{~cm}$ spray contacting height (distance between distributors) or a $155 \mathrm{~cm}$ packing height, with $50 \mathrm{~cm}$ coalescing sections at each end. The performance of five different packing elements was compared with that of an empty (spray) column. Two different chemical systems were used: toluene-acetonewater, and 1-butanol-succinic acid-water. Fundamental models were developed to account for the flooding, dispersed-phase holdup, and mass transfer efficiency.

Kumar and Hartland [42] presented empirical correlations which reproduce the slip velocity data over a wide range of variables. Using a large bank of published data (3,700 data points) empirical equations, not including the holdup for each of 
the columns, were suggested for pulsed perforatedplate, Karr reciprocating-plate, rotating disc and spray extraction columns [42]. According to these authors, the presented equations are simpler and more exact than previously published empirical correlations involving the characteristic velocity. Explicit correlations for the holdup in both the loose and densely-packed regions of operation in spray columns are also presented, which do not involve the slip velocity [42].

On the basis of a large number of published experimental results for eight different types of extraction columns, namely rotating disc, asymmetric rotating disc, Kühni, Wirz-II, pulsed perforatedplate, Karr reciprocating-plate, packed, and spray columns, a unified correlation for the prediction of the dispersed-phase holdup was presented by Kumar and Hartland [43, 44]. The analysis of data with and without mass transfer showed that the holdup can be expressed in terms of the mechanical power dissipation, phase flow rates, physical properties, and column geometry. The limitations of previously published correlations with regard to their application and solution were demonstrated.

In order to improve the correlation for the slip velocity given by $E q$. (7), Sovilj [18] redefined this equation by adding a dimensionless group $\left(U_{\mathrm{d}} d_{\mathrm{N}} \Delta \rho / \sigma\right)$ :

$\frac{U_{s}^{2}}{d g}=4.436\left(\frac{\Delta \rho}{\rho_{c}}\right)^{1.135}\left(\frac{1-\varepsilon_{d}}{1+\varepsilon_{d}^{1 / 3}}\right)^{2.729}\left(\frac{U_{d} d_{N} \Delta \rho}{\sigma}\right)^{-0.018}$

The AARD for $E q$. (9) was $9.6 \%$. Good agreement between the experimental and predicted values of the slip velocity by $E q$. (9) was obtained over a wide range of holdups (0.01 to 0.362 ) and Reynolds numbers (59 to 1,067). Peterson [45] presented an investigation of the spray L-L extraction column operation using the hexane-water system, with particular emphasis on the relationship between flow rates and dispersed-phase holdup. A preliminary study was made in a $4.445 \mathrm{~cm}$ outside diameter column to determine the mechanism of drop formation. At low dispersed-phase rates, drops of equal size formed on the dispersion plate. As the flow increased, a cone of dispersed fluid built up into the continuous phase and the drops broke off the tip of the cone in a variety of sizes. From tests performed in this small column (with a few holes in the dispersion plate), it is possible to predict the performance of a plate with a large number of holes with respect to drop formation and approximate drop size distribution. This prediction is from the pressure drops across the plate in both cases.
It is known that packing in the packed bed column helps to break up the drops of the dispersed liquid phase and can effectively inhibit the continuous phase from axial dispersion in the column [46]. Unlike in spray columns, the pressure drop in packed columns cannot be directly estimated for the dispersed-phase holdup. However, if an increase is made for the net downward or upward thrust on the packing because of the flow of the two phases in the column, it may be possible to estimate the pressure drop from the holdup data. The study of the dispersed-phase holdup in packed columns is, therefore, essential to understand the mechanics of the operation of L-L extraction columns. The earliest measurement of the dispersedphase holdup was made by Appel and Elgin [26]. Pratt and co-workers [46, 47], and Laddha and coworkers [48-50], gave effective correlations for the holdup estimation in packed extraction columns.

Gaylar and Pratt [46] correlated the slip velocity of the dispersed-phase drops relative to the moving continuous phase in a packed bed column by the following expression:

$$
U_{s}=\frac{U_{d}}{e \varepsilon_{d}}+\frac{U_{c}}{\left[e\left(1-\varepsilon_{d}\right)\right]}=U_{0}\left(1-\varepsilon_{d}\right)
$$

Equation (10) was redefined in the following shape:

$$
\frac{U_{d}}{\varepsilon_{d}}+\frac{U_{c}}{\left(1-\varepsilon_{d}\right)}=C B\left(1-\varepsilon_{d}\right)
$$

where the relationship for $C B$ was defined by dimensionless analysis [46]:

$$
C B=C_{11}\left[\frac{A /\left(e^{3} g\right)}{\rho_{c} / \Delta \rho}\right]^{-0.5}
$$

where $C_{11}$ is the constant.

By substituting the expression for $C B$ from $E q$. (12) into $E q$. (11), it is possible to obtain the following generalized correlation for some of the packing elements, such as Raschig rings, Lessing rings and Berl saddles [46]:

$$
\left[\frac{U_{d}}{U_{c}}+\frac{\varepsilon_{d}}{\left(1-\varepsilon_{d}\right)}\right]\left[\frac{U_{c}^{2} A}{g e^{2}}\left(\frac{\rho_{c}}{\Delta \rho}\right)\right]^{0.5}=0.683 \varepsilon_{d}\left(1-\varepsilon_{d}\right)
$$

The experimental data for Berl saddles and systems: a) $10 \%$ glycerol-kerosene $(10.16 \mathrm{~cm}$ i.d. tower, $20.0 \mathrm{~mm}$ Berl saddles), b) $20 \%$ glycerolkerosene $(10.16 \mathrm{~cm}$ i.d. tower, $9.525 \mathrm{~mm}$ Berl saddles), and c) water-kerosene (10.16 cm i.d. tower, $12.5 \mathrm{~mm}$ Berl saddles) [46] were plotted in terms of the following values: 


$$
\left[\frac{U_{d}}{U_{c}}+\frac{\varepsilon_{d}}{\left(1-\varepsilon_{d}\right)}\right]\left[\frac{U_{c}^{2} A}{g e^{2}}\left(\frac{\rho_{c}}{\Delta \rho}\right)\right]^{0.5} \text { VS. } \varepsilon_{d}\left(1-\varepsilon_{d}\right)
$$

It was observed from the mathematical analysis of the data presented in previous work that they agree with the correlation proposed by $\mathrm{Si}$ taramayya and Laddha [48]. These data show an AARD of $9.09 \%$ and maximum deviation of $\pm 26.94 \%$.

In the case of spheres as packing elements, when the data were expressed in terms of Eq. (14), a straight line of a 0.973 slope was obtained by the mathematical analysis of the data and compared to 0.683 for Raschig rings, Lessing rings, and Berl saddles. The average percentage deviation of all points for spheres was $10.86 \%$ and the maximum deviation was $\pm 31.48 \%$. Eighty-nine per cent of all the points had an error of $\pm 15 \%$.

\subsection{Dispersed-phase holdup and drop size}

The knowledge of drop size is of fundamental importance in the design of L-L extraction columns. Because of its effect on the mass transfer coefficient, dispersed-phase drop behavior is one of the most important parameters in L-L extraction columns [10]. Drop size affects the dispersedphase holdup and residence time and allows throughputs. It is by no means easy to predict the drop diameter as a function of the column geometry, physical properties of the L-L system, and the direction of mass transfer. Kumar [51] investigated the behavior of L-L extractors, with special reference to spray columns, pulsed sieve-plate columns and mixer-settlers. Drops in spray columns can be formed individually or by the breakup of jets. Based on 484 data points for 12 L-L systems from 8 different sources, correlations of drop size were developed for the single drop and jetting regions in terms of physical properties and nominal nozzle velocity which predicted the drop diameter with an AARD of $9.7 \%$. A general correlation treating nozzle velocities up to the critical velocity was also presented which predicted the drop size with an AARD of $9.5 \%$. The concept of slip velocity was used to correlate the dispersed phase hold-up in spray columns. The drag coefficient defined by Barnea and Mizrahi [52] was modified and the slip velocity data in the intermediate zone and lower range of the turbulent zone correlated. The proposed correlation, which predicts two values of the dispersed-phase holdup corresponding to loose and dense-packed dispersions, has a practical value of a simple correlation over the determined range of the Reynolds numbers covered.
The average drop size in most of the investigated two-phase liquid-liquid systems can be expressed as the Sauter mean drop diameter, $D_{32}$, in the form:

$$
D_{32}=\frac{\sum n_{i} d_{i}^{3}}{\sum n_{i} d_{i}^{2}}
$$

Seibert and Fair [11] proposed a new equation for the prediction of the Sauter mean drop diameter in spray and packed extraction columns, which was independent of the phase velocities, as follows:

$$
D_{32}=1.15 \eta\left(\frac{\sigma}{\Delta \rho g}\right)^{0.5}
$$

where $\eta$ is a correction factor calculated from the experimental drop diameter data downloaded from the literature. Its values are $\eta=1.0$ for no mass transfer or transfer from the continuous to the dispersed phase and $\eta=1.0-1.8$ for mass transfer from the dispersed to the continuous phase. Perrut and Loutaty [53] presented an empirical relation for the Sauter mean drop diameter as a function of Eö number, as follows:

$D_{32}=2.07$ (1-0.193E0̈), $0.011<$ EÖ $<1.70$

Vedaiyan et. al. [54] developed a correlation for $D_{32}$ in the shape:

$$
D_{32}=1.592\left(\frac{U_{N}^{2}}{2 g d_{N}}\right)^{-0.0665}\left(\frac{\Delta \rho g}{\sigma}\right)^{-0.5}
$$

Kumar and Hartland [55] presented an equation for the limiting value of drop size in the absence of agitation or at low levels of agitation in L-L extraction columns in the following form:

$$
D_{32}=\mathrm{C}_{12}\left(\frac{\sigma}{\Delta \rho g}\right)^{0.5}
$$

where $\mathrm{C}_{12}$ is the constant, which is a function of the column geometry, mass transfer, and characteristics of the L-L system investigated. For example, for the L-L system n-butyl alcohol-water, constant $\mathrm{C}_{12}=1.3$ in a rotating disk column, but in pulsed perforated-plate columns constant $\mathrm{C}_{12}=0.92$ [50]. Kumar and Hartland [55] also showed a new empirical relation in which $D_{32}$ was a function of the Weber and Eötvös numbers:

$$
D_{32}=1.59 d_{\mathrm{N}} W e^{-0.068} E \ddot{o}^{-0.278} \text { for } 0<W e<2
$$

The AARD for this equation was $11.87 \%$ [49]. Varfolomeev et al. [38] presented two correlations for the prediction of the Sauter mean drop diameter for spray extraction columns: 


$$
\begin{array}{r}
E \ddot{o}_{\mathrm{d}}=2.86 \operatorname{Re}_{\mathrm{N}}^{-0.125} \mathrm{~S}^{-0.043} \text { for } R e_{\mathrm{N}}=4.6-190(21) \\
E \ddot{o}_{\mathrm{d}}=0.86 \operatorname{Re}_{N}^{-0.125} S^{-0.043}\left(1-\varepsilon_{\mathrm{d}}\right)^{-1.5}\left(\frac{\mu_{d}}{\mu_{c}}\right)^{-0.65}
\end{array}
$$

for

$$
R e_{\mathrm{N}}=430-1200
$$

The drops in the packed columns were determined simply by the ratio of interfacial tension to buoyancy forces, the constant of proportionality in the correlation being a function of the physical properties. The treatment of spray columns was similar to that used for agitated columns, except that the drop size at high nozzle velocities (jetting region), was regulated by the ratio of interfacial to kinetic energies [38].

Kumar and Hartland [55] developed unified correlations of the Sauter mean drop diameter in eight different types of extraction columns, namely, rotating disc, asymmetric rotating disc, Kühni, Wirz-II, pulsed perforated-plate, Karr reciprocating-plate, packed, and spray columns. The equation for the spray extraction column was:

$$
D_{32}=\frac{c o}{C K\left(\frac{6 d_{N \sigma}}{\Delta \rho g}\right)^{\frac{1}{3}}}+\frac{1}{C L\left(\frac{12 \sigma}{\rho_{d} U_{N}^{2}}\right)}
$$

On the basis of 743 measurements, the values of parameters $C K$ and $C L$ determined by using Marquardt`s algorithm [56] were 1.0 and 2.04, respectively. The data for $c \rightarrow d$ direction of heat and mass transfer were found not to be significantly different from those without transfer, so $C O=1.0$ for these two cases. For $d \rightarrow c$ transfer, the optimized value of $C O$ was 1.06 . The AARD in the predicted values of $D_{32}$ from the experimental points was $13.0 \%$ [55].

The correlation for the packed bed extraction columns given by the same authors [55] has the following shape:

$$
D_{32}=0.74 C C\left(\frac{\Delta \rho \rho_{d} \sigma}{\rho_{W}^{2} \sigma_{W}}\right)^{-0.12}\left(\frac{\sigma_{W}}{\Delta \rho g}\right)^{0.5}
$$

in which $\rho_{w}=998.0 \mathrm{~kg} / \mathrm{m}^{3}$ is the density of water and $\sigma_{w}=0.0728 \mathrm{~N} / \mathrm{m}$ is the surface tension of water at 20 ${ }^{\circ} \mathrm{C}$. The values of $C C$ are 1.084 , and 1.23 for no mass transfer and $c \rightarrow d$, as well as $d \rightarrow c$ directions of mass transfer, respectively. Equation (24) reproduces the drop size data in an AARD of $15.7 \%$.

Chun and Wilkinson [57] measured the drop size and holdup in a continuous counter-current extraction spray column of a $22.7 \mathrm{~mm}$ i.d. under near-critical and supercritical conditions. The drop size was measured by the analysis of images and the dispersed-phase holdup by the shut-off method.
The systems studied were 2-propanol-water (5 and 10 vol. \%) and ethanol-water (10 vol. \%) extracted with carbon dioxide, at temperatures from 25 to $45^{\circ} \mathrm{C}$ and pressures from 6.9 to $13.8 \mathrm{MPa}$. The experimental data were correlated with the physical properties of the system and the flow characteristics:

$$
D_{32}=1.909 \mathrm{~d}_{\mathrm{N}} W e^{-0.0028} E \ddot{O}^{-0.1457} \text {, }
$$

for

$$
0.005<W e<2
$$

The model developed to predict the drop size agreed successfully with the experimental data, with an AARD of $17.85 \%$ [57].

Ghorbanian et al. [29] measured the size of drops in an extraction spray column by the direct photography method and obtained the Sauter mean drop diameter accordingly. They then assessed two types of models using dimensionless analysis and appropriate software. In the first type of models, the correlation was established based on dimensionless parameters similar to accessions defined by other researchers:

$$
\frac{D_{32}}{d_{N}}=2.05306336 W e^{0.031179} E \ddot{O}^{-0.2622783}
$$

where $W e$ is the Weber number, and $E \ddot{O}$ is the Eötvös number. This model has a strong statistical basis and can predict $D_{32}$ very well. The $A A R D$ was $7.92 \%$. In the spray column [29] five chemical systems with different interfacial tensions were used: a) butanol-water, b) benzene-water, c) toluene-water, d) cumene-water, and e) heptane-water. In the second type of models, dimensional parameters were used, and therefore a new model was introduced for multi-drop extraction columns:

$$
D_{32}=d_{N}^{0.496302} \sigma^{0.221950}(\Delta \rho)^{-0.227903} U_{N}^{0.064360}
$$

In the second type, four dimensional parameters $\left(d_{N}, \sigma, \Delta \rho, U_{N}\right)$ were selected as the most effective variables on drop size diameters, and modelling results showed prediction of drop size diameters with an $A A R D$ of $5.82 \%$. In other cases, without using " $U_{N}$ " as a variable, the amount of error was decreased to $5.73 \%$, which showed better fitting.

The effect of the holdup on the Sauter mean drop diameter and the effect of $D_{32}$ on the terminal velocity were investigated in a spray extraction column [58]. Three L-L systems were used in the experiments: toluene-acetone-water, n-butanolacetone-water, and cumene-acetone-water. An increase in the holdup had two special effects on the 
mean drop size, $D_{32}$. At first, $D_{32}$ increased with increasing holdup, but when the holdup values exceeded a specific point, $D_{32}$ decreased with an increase in the holdup. Therefore, the $D_{32}$ holdup curve would have a maximum. In addition, the smallest and largest $D_{32}$ referenced to the nbutanol-water-acetone system and the cumenewater-acetone system, respectively. The terminal velocity increased with the enhancement of $D_{32}$. After reaching a maximum, the terminal velocity diminished with increased $D_{32}$. Moreover, the terminal velocity of the n-butanol-water-acetone system was less sensitive to $D_{32}$ growth in comparison with that of the other two systems [58]. Empirical correlations derived to predict $D_{32 \max }$ and the terminal velocity were in good agreement with the experimental data. The derived correlations were compared with other researchers' work and the results were in satisfactory conformity [58]. According to the general equation obtained by using dimensionless analysis, in which $D_{32}$ is a function of phase velocities, physical characteristics of liquid phases, gravity acceleration, the dispersedphase holdup, and nozzle diameter, SalimiKhorshidi et al. [58] derived a correlation for the maximum value of $D_{32}$, as follows:

$$
\frac{D_{32 \max }}{d_{N}}=1.33 \varepsilon_{d}^{0.51} W e_{c}^{-0.16} R e_{c}^{0.31}
$$

The $A A R D$, calculated from the standard relation for all the liquid-liquid systems, was $5.64 \%$.

It is significant that, in this paper [58], the maximum Sauter mean drop diameter was investigated and correlated for the first time in a spray extraction column. By comparing the final selected correlation with the experimental data, it was observed that the correlation mentioned above had an error of about $4.22 \%$ compared to the empirical data that showed good accuracy of this correlation. The effects of the holdup on the Sauter mean drop diameter in spray and packed extraction columns were also studied by Salimi-Khorshidi et al. [58]. They determined that $D_{32}$ was smaller for the packed column in comparison with that of the spray column. Furthermore, for both packed and spray columns, two well-defined regions for the dependence of $D_{32}$ on the holdup were observed. The Sauter mean drop diameter increased and decreased with an increase in the holdup at low and high levels of the holdup, respectively [58].

On the basis of experimental data for the LL system toluene-acetone-water, Salimi-Khorsidi et al. [58] suggested two equations for spray and packed bed columns, respectively:

$$
\begin{aligned}
& \frac{D_{32}}{d_{\mathrm{N}}}=8.60\left(1-0.78 \varepsilon_{d}\right)^{1.65} W e_{d}^{0.42} R e_{d}^{-0.51} \\
& \frac{D_{32}}{d_{\mathrm{N}}}=4.98\left(1-1.05 \varepsilon_{d}\right)^{0.64} W e_{d}^{0.26} R e_{d}^{-0.26}
\end{aligned}
$$

The AARD was $1.69 \%$ and $1.79 \%$ for spray and packed bed extraction columns, respectively.

The experimental data for the tolueneacetone-water system were determined in a glass column with an inside diameter of $6.0 \mathrm{~cm}$ and a height of $120 \mathrm{~cm} \mathrm{[59].} \mathrm{The} \mathrm{column} \mathrm{was} \mathrm{randomly}$ loaded with Raschig ring packing (stainless steel with a height and diameter of $1 \mathrm{~cm}$ ). The column was used as a spray extraction and a packed bed column, alternately. The authors [59] compared the derived Eq. (29) with Varfolomeev's equations [38], i.e. Eq. (21) and Eq. (22). On the other hand, $E q$. (30) was compared with GhaffariTooran's experimental data [59]. The deviation of Eq. (29) from Varfolomeev's correlations was equal to 28.5 $\%$. At the same time, Eq. (30) had a variance of about $16.8 \%$ from Ghaffari Tooran's [59] experimental data.

\subsection{Axial dispersion coefficient}

An important factor in understanding the fundamental transfer mechanism in counter-current liquid-liquid spray and packed extraction columns is the effect of the continuous-phase axial mixing (back-mixing). Both stage-wise and differential (diffusion) models may be used [60-69]. For comparative purposes, it is better to express the amount of back-mixing as the axial dispersion coefficient related to the diffusion model than as the backflow coefficient used in the stagewise model. Hazlebeck and Geankoplis [61] studied the values of axial dispersion coefficients experimentally in a spray extraction column with the L-L system methyl isobutyl ketone (MIBK)-water, in which water was the continuous and MIBK the dispersed phase, and compared their results with Brutvan [62], who studied axial dispersion in the aqueous continuous phase with 3-, 4-, 5-, and 6-mm glass beds as the dispersed phase. Hazlebeck and Geankoplis [61] used a column with a $3.5 \mathrm{~cm}$ i.d. and a length of $93.0 \mathrm{~cm}$, and Brutvan's columns had a 2.54-, a $3.81-$, and a $5.08 \mathrm{~cm}$ i.d. and a length of 151.13 $\mathrm{cm}$. Brutvan [62] found that the axial dispersion coefficient, $E_{c}$, decreased with increased continuous-phase velocity, $U_{c}$, and concluded that an increase in the dispersed-phase flow rate, $U_{d}$, corresponded to a slight increase in the axial dispersion coefficient. For packed beds, $E_{c}$ varied as $U_{c}^{1.0}$. Brutvan [62] found that $E_{c}$ increased with column diameter, and that it decreased as the particle size 
increased at constant velocities of the phases. His values for $P e_{c}$ number were considerably lower for the spray column than those found for packed beds.

Hazlebeck and Geankoplis [61] did not measure the drop size, but it was probably about $0.4304 \mathrm{~cm}$, as pointed out by Henton and Cavers [64]. In the work [61], $E_{c}$ values varied directly as the continuous-phase velocity to the 0.45 power $\left(U_{c}^{0.45}\right)$ and were much higher than those found for packed beds of spheres. Hazlebeck and Geankoplis [61] concluded that $E_{c}$ was independent of the dispersed-phase velocity over the $U_{d}$ range of 8.44 to $10.30 \mathrm{~cm} / \mathrm{s}$. The Peclet number varied from 0.008 to 0.023 , and these values were about $1 / 10$ as large as those found for packed beds of spheres. The experimental data for the axial dispersion coefficient, $E_{w}$, was plotted $v s$. the continuous-phase velocity [61]. Equation (31) for the best line through the data presented in Table 1 . These values of $E_{c}$ at a given velocity $U_{c}$ are several fold greater than the values for packed bed extraction columns [61]. On the other hand, on the basis of many literature data, Hazlebeck and Geankoplis [61] presented the following empirical correlation, Eq. (32), Table 1 , where $\mathrm{a} 1$ and $\mathrm{b} 1$ are the constants characteristic of the system investigated.

\section{Table 1}

The correlations of the axial dispersion coefficient for spray extraction columns

\begin{tabular}{lcl}
\hline \hline Equation & Number of equation & References \\
\hline $\mathrm{E}_{\mathrm{c}}=9.00 U_{c}^{0.45}$ & $(31)$ & Hazlebeck, Geankoplis [61] \\
$\frac{U_{c} d_{p}}{E_{c}}=\mathrm{a} 1\left(\frac{U_{c} d_{p} \rho_{c}}{\mu_{c}}\right)^{b 2}$ & $(32)$ & Hazlebeck, Geankoplis [61] \\
$\frac{E_{\mathrm{c}}\left(1-\varepsilon_{\mathrm{d}}\right)}{U_{c} \mathrm{~d}_{\mathrm{p}}}=\mathrm{f}\left(\frac{U_{s d_{p} \rho_{c}}}{\mu_{c}}\right)$ & $(33)$ & Henton, Cavers [64] \\
$\frac{E_{c}}{v_{c}}=6.5\left(\frac{U_{s} d_{h} \rho_{c}}{\mu_{c}}\right)^{0.987} \varepsilon_{d}^{0.814} \mu^{3.89}$ & $(34)$ & Zheleznyak, Landau [66] \\
$\left(\frac{U_{c} D_{32}}{E_{c}}\right)\left(\frac{U_{d}}{U_{c}}\right)^{0.5}=\mathrm{a} 2 \mathrm{EXP}\left(b 2 \frac{U_{N} d_{N} \rho_{c}}{\mu_{c}}\right)$ & $(35)$ & Laddha et al. [68] \\
$E_{c}=3.43 \times 10^{-4} U_{c}^{0.42}$ for $U_{c} \leq 4.5 \mathrm{~mm} / \mathrm{s}$ & $(36)$ & Geankoplis et al. [69] \\
\hline \hline
\end{tabular}

Henton [63] studied the back-mixing of the continuous phase in L-L spray columns of various geometries for various flow rates of the two phases and drop size distributions. The axial mixing of the continuous phase was characterized by the dispersion or eddy diffusion model. The axial eddy diffusivities from the results of Henton [63] were calculated by the steady-state form of the model, to determine whether the axial eddy diffusivity was independent of the continuous-phase flow rate and column height. Low dispersed-phase flow rates and large drop sizes resulted in high axial eddy diffusivities. Increasing the column diameter to $7.62 \mathrm{~cm}$ resulted in superficial axial eddy diffusivities between 6.3 and 17.3 times larger [63]. The holdup increased approximately linearly with increasing dispersedphase velocity and tended to be slightly higher for increased continuous-phase superficial velocities. A smaller drop size resulted in an increased holdup [63]. The mixing cell-packed bed analogy was used to predict the Peclet numbers in a spray column. The agreement between these and the measured Peclet numbers was good for drops of about $0.381 \mathrm{~cm}$ and $0.15 \mathrm{~cm}$, but became progressively worse as the drop size was reduced [63].
Henton and Cavers [64] investigated the axial dispersion in the MIBK-water system, in which water was the continuous and MIBK the dispersed phase. With the exception of one experiment with a $7.62 \mathrm{~cm}$ i.d. column, they used $3.81 \mathrm{~cm}$ i.d. columns. Henton and Cavers used the diffusion model to express the axial dispersion coefficient in the continuous phase of an L-L spray column. They found that $E_{c}$ was unaffected by $U_{c}$ over the velocity range investigated, but decreased with increased $U_{d}$. It increased with drop size at constant dispersed-phase velocity. However, $E_{c}$ remained approximately constant with drop size when the number of drops per unit volume of column was kept constant. It was found that $E_{c}$ increased with column diameter but was unaffected by column length. Based on their experimental data, Henton and Cavers [64] suggested Eq. (33), Table 1, which is a function of modified $P e_{c}$ and $R e_{c}$ numbers.

Hozawa et al. [65] carried out experiments on the longitudinal mixing characteristics of the L-L spray column by the rectangular pulse response method using $0.2 \mathrm{~N} \mathrm{KCl}$ solutions as the tracer and changing the orifice numbers and sizes of the distributor. Water and toluene were selected for the 
continuous and dispersed phase, respectively. The dispersion model was found to express well the longitudinal mixing of the continuous phase. The axial dispersion coefficient was correlated as a function of the orifice diameter and the slip velocity between the dispersed and continuous phase. Zheleznyak and Landau [66] developed a new equation based on the experimental data in which the continuous phase was a liquid, but liquid, gas or solid particles were used as the dispersed phase, Eq. (34), Table 1. The best results in the correlation of the experimental data by Eq. (34) were obtained when solid particles were used as the dispersed phase.

Henton et al. [67] investigated the analogy between the flow of a single-phase fluid through a packed bed and through a series of perfect mixers and extended it to L-L spray tower operation. The Peclet numbers for the continuous phase were possible to predict directly from the dispersed-phase holdups. Agreement with the experiment was reasonably good for MIBK drops dispersed in water in a $3.81 \mathrm{~cm}$ i.d. column if the drop size was either $0.36 \mathrm{~cm}$ or $0.41 \mathrm{~cm}$. Laddha et al. [68] presented new data on the residence time distribution (RTD), axial mixing, and the Peclet numbers for both phases in the spray column for the MIBK-water liquid-liquid system. MIBK was dispersed in water. The drop size distribution was of major interest. The continuous-phase velocities affected RTD variance at high flow without a noticeable effect on the dispersed-phase RTD variance. Laddha et al. proposed a new empirical correlation, Eq. (35), Table 1, which was based on the variables in the function of the hole diameter of the distributor. In the two-phase MIBK-water system, the constants had the following values: $a_{2}=14 \times 10^{-3}$ and $b_{2}=5$ $\times 10^{-4}$. The correlation given by $E q$. (35) was checked in a relatively small number of two-phase systems and the values of AARD for the modified Peclet number were $\pm 19.0 \%$ [68].

Geankoplis et al. [69] experimentally obtained the longitudinal dispersion coefficients of the continuous phase in spray type L-L extraction columns. They used columns of different lengths $(2.0-, 33.0-, 93.0-$, and $174.0 \mathrm{~cm})$ and two internal column diameters, of $2.70-$ and $3.58 \mathrm{~cm}$. The L-L system used was MIBK-water, in which water was the continuous and MIBK the dispersed phase. The method used was unsteady-state measurements of a $0.1 \mathrm{~N} \mathrm{KCl}$ solution as the tracer. Increases in the continuous-phase velocity greatly increased the axial dispersion coefficient and increases in the dispersed-phase velocity decreased $E_{c}$. Small dispersion coefficients were found for small tower length and these coefficients increased as the tower length increased. Also, at long lengths, where the end effects become negligible, $E_{c}$ was independent of the length. A decrease in tower diameter from $3.58 \mathrm{~cm}$ to $2.70 \mathrm{~cm}$ caused a decrease in $E_{c}$ of approximately $20 \%$ for a range of continuous-phase velocities. A comparison of the Peclet and Reynolds numbers for spray towers with those for packed beds gave comparable values, indicating that a spray tower could be calculated as a diluted packed bed tower with a very high void fraction for the continuous phase. Using the data from this work and the data presented by Geankoplis et al. [69], the following equation, Eq. (36), Table 1, was obtained using the method of least squares [69]. The correlation coefficient in Eq. (36) is 0.94, with an average deviation of $\pm 8 \%$.

Sovilj et al. [32] obtained the values of axial dispersion coefficient in the continuous phase for the toluene-water system in pilot plant extraction column. Dependence of the data for the Peclet number as function of the Reynolds number $\left(R e_{c}\right)$ for two-phase system is presented in Figure 2. It is evident from Figure 2 that when the Reynolds number increased, the Peclet number $\left(P e_{c}\right)$ increased too.

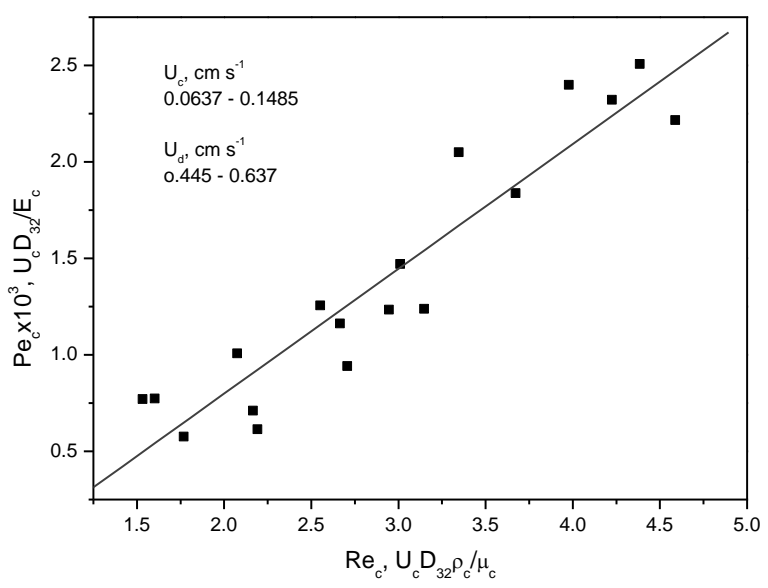

Fig. 2. Reynolds $\left(R e_{c}\right)$ and Peclet $\left(P e_{c}\right)$ numbers relationship $\left(\mathrm{d}_{\mathrm{N}}=0.15 \mathrm{~cm}\right)($ Source: Sovilj et al. [32] $)$

Moon et al. [70] investigated the hydrodynamics of a packed column for the water (continuous)-di-isobutyl ketone (dispersed) system. Two columns were used for their investigation: one for the low Reynolds number regime of single-phase flow, and the other for two-phase flow. To obtain a low Reynolds number value while maintaining a relatively small liquid-phase Schmidt number, glass beads of $0.01472 \mathrm{~cm}$ in diameter were packed into a cylindrical column of $15.875 \mathrm{~cm}$ in diameter and $67.056 \mathrm{~cm}$ high, fitted with 200-mesh stainless steel screens at each end between the grid 
plate and the packing. The other column used for the two-phase investigation was packed with 1.905 $\mathrm{cm}$ ceramic Raschig rings. They observed that the Peclet numbers were equal for the same Reynolds numbers, regardless of viscosity. They formed a comparison of their data on the liquid phase with experimental results obtained by McHenry and Wilhelms [71] for the gas phase, and proposed an explanation for the difference between gas and liquid Peclet numbers of transverse molecular diffusion in the packing void spaces. They suggested that at low Reynolds numbers, when "Taylor diffusion" controls the dispersion behavior, the Peclet number is inversely proportional to the Reynolds number:

$$
\frac{\varepsilon p\left(U_{01} d_{p p}\right)}{D_{m}}=\frac{K_{1}}{\left[\frac{v_{c}}{D_{m}}\left\{\frac{U_{01} d_{p p \rho_{c}}}{\mu_{c}(1-\varepsilon p)}\right]\right.}
$$

where $K_{l}$ is the constant. Also, at very low Reynolds numbers, when axial molecular diffusion is controlled, the Peclet number decreases proportionally to the Reynolds number:

$$
\frac{\varepsilon p\left(U_{01} d_{p p}\right)}{D_{m}}=K 2\left(\frac{v_{c}}{D_{m}}\right)\left[\frac{U_{01} d_{p p} \rho_{c}}{\mu_{c}(1-\varepsilon p)}\right]
$$

Constant $K 2$ depends on the porosity of the packing and the velocity profile of the fluid. The axial Peclet number of the wetting dispersed phase decreases somewhat with decreasing continuous-phase flow rate and with increasing dispersed-phase flow rate. For the non-wetting dispersed phase, the Peclet number remains practically constant over the full range of $U_{c 0}$ and $U_{d 0}$ values studied $\left(U_{\mathrm{c} 0}, U_{\mathrm{d} 0}, \mathrm{~m} \mathrm{~s}^{-1}\right.$, are the overall interstitial velocity of continuous and dispersed phase, respectively). These variables are the overall interstitial velocities of the continuous and the dispersed phase. The other parameters are expressed in the same form as in Eq. (37).

The rise in Peclet numbers at low Reynolds numbers, anticipated by Hennico et al. [72], does not occur, down to Reynolds numbers as low as 0.04 . The continuous-phase Peclet number is not affected by changes in the physical properties of the dispersed phase; however, the effect of the dispersed-phase density and viscosity changes was not studied. The Peclet number of the dispersed phase decreases as the continuous-phase flow rate increases, at constant dispersed-phase flow rate. Higher dispersed-phase Peclet numbers were obtained for the system di-isobutyl ketone-water than for kerosene-water. This is believed to be due to a decreased average size of the dispersed-phase drops. Delgado [73] summarized and reviewed the phenomenon of dispersion (transverse and longitudinal) in packed beds for a great deal of information from the literature. Dispersion plays an im- portant part in, for example, contaminant transport in ground water flows, miscible displacement of oil and gas, and reactant and product transport in packed bed reactors. There are several variables that must be considered in the analysis of dispersion in packed beds, such as the length of the packed column, viscosity and density of the fluid, ratio of column diameter to particle diameter, ratio of column length to particle diameter, particle size distribution, particle shape, effect of fluid velocity, and effect of temperature (or Schmidt number). Empirical correlations represented for the prediction of dispersion coefficients.

Han et al. [74] investigated the longitudinal and lateral dispersion coefficients at various axial positions in a packed bed in the Peclet number range from $10^{2}$ to $10^{4}$. Three different types of packing elements were used: uniform size particles, narrow size distribution, and wide size distribution. In the case of uniform particles, the longitudinal dispersivities were found to be strong functions of the position in the bed unless the dispersion length satisfied a constraint dependent on the value of the Peclet number. Generally, the larger the Peclet number, the larger the required length for constant axial dispersivities to be achieved. In the case of wide size distribution, the longitudinal dispersivities were larger than in the uniform particle case, and they required a longer dispersion length to achieve a constant value. This suggests a characteristic length for dispersion larger than the mean hydraulic radius. The lateral dispersivities were found to be insensitive to the distribution of particle sizes or location in the bed. Han et al. [74] showed that the values of the longitudinal dispersion coefficient, for uniform-size packed beds, measured at different positions in the bed are a function of bed location unless the following approximate criterion is satisfied:

$$
\frac{L}{d_{p p}} \frac{1}{P e_{m}}\left(\frac{1-\varepsilon}{\varepsilon}\right)^{2} \geq 0.30 \text { or } \theta=\frac{D_{m} t}{d_{p p}^{2}} \geq 0.15
$$

These authors showed that for $P e_{m}<700$, the longitudinal dispersion coefficients were nearly identical for all values of $x=\mathrm{L}$, and for $P e_{m}>700$ they observed an increase in the value of dispersion coefficients with increasing distance down the column.

Chung and Wen [75] developed an equation for the Peclet number based on the particle diameter, $P e_{p}$, in the following shape:

$$
\varepsilon_{b} P e_{p}=0.2+0.011 R e_{p}^{0.48}
$$

Ligny [76] presented a simple correlation which consisted of two empirical relations. The 
former lacks the molecular diffusion term, $D_{m}$, and the latter does not consider bed voidage:

$$
\frac{1}{P e_{p}}=\frac{0.7 D_{m}}{2 R_{p} U_{i t}}+\frac{1}{\left(0.4+\frac{1.76 D_{m}}{R_{p} U_{i t}}\right)}
$$

In the work of Rastegar and Gu [77], a new correlation for the axial dispersion coefficient was obtained using experimental data in the literature for axial dispersion in fixed-bed columns packed with particles.

$$
\frac{1}{P e_{p}}=\frac{0.7 D_{m}}{2 R_{p} U_{01}}+\frac{\varepsilon_{b}}{\left(0.18+0.008 R e_{k}^{0.59}\right)}
$$

The new axial dispersion coefficient correlation in this work [77] was based on additional experimental data in the literature by considering both molecular diffusion and bed voidage. It is more comprehensive and accurate. The Peclet number correlation from the new axial dispersion coefficient correlation leads to $12 \%$ lower Peclet number values on average, compared with the values from the Chung and Wen correlation, Eq. (40), and is, in many cases, much smaller than those from the De Ligny correlation, Eq. (41).

\section{CONCLUSIONS}

Hydrodynamic characteristics of different spray and packed extraction columns were compared. The behavior of two-phase liquid-liquid systems in spray and packed extraction columns was reviewed. The experimental values of slip velocity, dispersedphase holdup, mean drop size, and axial dispersion coefficient in two-phase systems from different literature sources were analyzed and discussed. The changes in slip velocity, the Sauter mean drop diameter and the axial dispersion coefficient as a function of the dispersed-phase holdup and phase velocities were presented and remarked up on. Empirical correlations for the slip velocity, the Sauter mean drop diameter and the axial dispersion coefficient, taken from the literature, were commented on and verified in terms of their applicability.

\section{REFERENCES}

[1] L. A. Robbins, R. W. Cusack, Liquid-liquid extraction operations and equipment. In: Perry's Chemical Engineers' Handbook R. H. Perry, D. W. Green (Eds.), Seventh Edition. McGraw-Hill Companies, Inc., 1997, pp. $1-47$.

[2] J. D. Thornton, Extraction, liquid-liquid. In: Thermopedia; A-to-Z Guide to Thermodynamics, Heat \& Mass Transfer, and Fluids Engineering(Authors) A. A. Ale- ksandrov, D. J. Archer, D. Arcoumanis, B. J. Azzopardi, Begell House, Begell Digital Portal, 2011.

DOI: 10.1615/AtoZ.e.extraction_liquid-liquid, accessed July 2018 .

[3] S. Mohanty, Modelling of Liquid-Liquid Extraction Column: A Review, Rev. Chem. Eng., 16 (3), 199-248 (2000). DOI: https://doi.org/10.1515/REVCE.2000.16.3.199

[4] N. N. Hidayah, S. Z. Abidin, The evolution of mineral processing in extraction of rare earth elements using liquid-liquid extraction: A review, Miner. Eng., 121, 146157 (2018).

DOI: https://doi.org/10.1016/j.mineng.2018.03.018

[5] D. F. Gerson, Liquid-Liquid Separations in Biotechnology. In: Biotechnology Research and Applications, J. Gavora, D. F. Gerson, J. Luong, A., Storer, J. H., Woodley (Eds), Springer, Dordrecht, 1988.

DOI: https://doi.org/10.1007/978-94-009-1371-4_10

[6] H. R. C. Pratt, G. W. Stevens. Design procedures for extractors with axial dispersion. In Science and Practice of Liquid Extraction, J. D. Thornton (Ed.), Oxford University Press. Oxford. Ch. 8, 1992.

[7] H. Zheng, W. Ren, K. Chen, Y. Gu, Z. Bai, S. Zhao, Influence of Marangoni convection on mass transfer in the n-propyl acetate/acetic acid/water system, Chem. Eng. Sci., 111, 278-285 (2014). DOI: https://doi.org/10.1016/j.ces.2014.02.015

[8] Koch Modular Process Systems, LLC. Typical Industrial Applications for Separation by Extraction, LiquidLiquid Extraction Equipment and Chemical Separation Solutions, https://kochmodular.com/liquid-liquid-extraction, accessed July 2018.

[9] J. Rauber, Design Practice for Packed Liquid/Liquid Extraction Columns, Sulzer Chemtech Ltd., Winterhtur, 2003, http://folk.ntnu.no/skoge/prost/proceedings/aiche2006/data/papers/P73337.pdf, accessed July 2018.

[10] R. M. Sá, L. M. N. Góis, C. F. Cavalcanti, Dispersed phase holdup in a liquid-liquid extraction column, Lat. Am. Appl. Res., 40, 373-376 (2010), ISSN 0327-0793. http://www.scielo.org.ar/pdf/laar/v40n4/v40n4a12.pdf, accessed July 2018.

[11] A. F. Seibert., J. R. Fair, Hydrodynamics and mass transfer in spray and packed liquid-liquid columns. Ind. Eng. Chem. Res., 27 (3), 470-481 (1988). DOI:10.1021/ie00075a017.

[12] J. Maćkowiak, Basic principles of packed column design for liquid/liquid systems. In: Fluid Dynamics of Packed Columns, Springer, Berlin Heidelberg, 2010, pp.315350. DOI:10.1007/b98397_7.

[13] G. A. Hughmark, Liquid-liquid spray column drop size, hold-up, and continuous phase mass transfer, Ind. Eng. Chem. Fund., 6 (3), 408-413 (1967). DOI:10.1021/i160023a014.

[14] R. Letan, E. Kehat, The mechanics of a spray column, AIChE J. 13 (3), 443-449 (1967). DOI:10.1002/aic.690130311.

[15] L. Steiner, S. Hartland, Neues zur mathematischen modellierung von flüssig/flüssig-extraktions kolonnen, Chem. Ing. Tech., 55 (3), 194-201(1983). DOI: https://doi.org/10.1002/cite.330550305

[16] M. Diaz, A. T. Aguayo, R. Alvarez, Hydrodynamics of liquid-liquid countercurrent extraction column with upflow gas agitation, Chem. Ing. Tech., 58 (1), 74-75 (1986). DOI: https://doi.org/10.1002/cite.330580127 
[17] M. Sovilj, G. Knežević, Gas-agitated liquid-liquid extraction in a spray extraction column, Collect. Czech. Chem. Commun., 59, 2235-2243 (1994).

DOI: https://doi.org/10.1135/cccc19942235.

[18] M. Sovilj, Axial dispersion in a three-phase gas-agitated spray extraction column, Collect. Czech. Chem. Commun., 63, 283-292 (1998).

DOI: https//doi.org/10.1135/19980283.

[19] J. Xiong, L. Zhang, Effects of gas-agitation and packing on hydrodynamics and mass transfer of extraction column, Can. J. Chem. Eng. , 82 (5), 1076-1080 (2004). DOI: https://doi.org/10.1002/cjce.5450820526

[20] Y. Cheng, L. Wang, Sh. Lü, Y. Wang, Zh. Mi, Gas-liquid-liquid three-phase reactive extraction for the hydrogen peroxide preparation by anthraquinone process, Ind. Eng.Chem. Res., 47(19), 7414-7418 (2008). DOI:10.1021/ie800500y.

[21] L. Steiner, M. Horvath, S. Hartland, Mass transfer between two phase in a spray column at the unsteady state, Ind. Eng. Chem. Process Des. Dev., 17 (2), 175-182 (1978). DOI:10, 1021/i260066a011.

[22] M. Sovilj, Slip velocity and hydrodynamic parameters in liquid-liquid spray columns, Collect. Czech. Chem. Commun., 54, 990-995 (1989). DOI:https://doi.org/1135/cccc19890990.

[23] M. N. Sovilj, Diffusion Operations, University of Novi Sad, Faculty of Technology, Novi Sad, 2004, pp 156192. (in Serbian).

[24] W. Batey, J. D. Thornton, Partial mass transfer coefficients and packing performance in liquid-liquid extraction, Ind. Eng.Chem. Res., 28 (7), 1096-1101 (1989). DOI: 10.1021/ie00091a032.

[25] Ch. E. Wicks, R. B. Beckmann, Dispersed-phase holdup in packed, countercurrent liquid-liquid extraction columns, AIChE J., 1 (4), (1955). DOI: 10.1002/aic.690010408.

[26] F. J. Appel, J. O. Elgin, Countercurrent extraction of benzoic acid between toluene and water - performance of spray and packed columns, I. E. C., 29, 451 (1937). DOI:10.1021/ie50328a022.

[27] A. Salimi-Khorshidi, H. Abolghasemi, A. Khakpay, Z. Kheirjooy, M. Esmaieli, Spray and packed liquid-liquid extraction columns: drop size and dispersed phase mass transfer, Asia-Pacific J. Chem. Eng., 8 (6), 940-949 (2013). DOI: https://doi.org/10.1002/apj.1739

[28] Z. Azizi, A. Rahbar, H. Bahmanyar, H. Abolghasemi, Mass transfer model for a single dropflow of two liquid phases in a structured packed column. In: Separation Processes: Emerging Technologies for Sustainable Development, P. K. Mishra, M. K.Mondal, P. Srivastava (Eds), Allied Publishers Pvt. Ltd., New Delhi, India 2009, pp. 291-299.

[29] S. A. Ghorbanian, H. Abolghasemi, S. R. Radpour, Modelling of mean drop size in an extraction spray column and developing a new model, Iran. J. Chem. Chem. Eng. Research., 30 (4), 89-96 (2011). www.ijcce.ac.ir/article_6094_b6b4ff3cbec22aa9d8bfbc8 4b51bfb88.pdf, accessed July 2018.

[30] M. Fourati, V. Roig, L. Reynal, Liquid dispersion in packed columns: experiments and numerical modelling. 11th International Conference on Gas-Liquid \& GasLiquid-Solid Reactor Engineering, Séoul, South Korea,
2013, pp.266-278. https://hal.archives-ouvertes.fr/hal00911059 , accessed July 2018.

[31] F. W. Keith, A. N. Hixson, Liquid-liquid extraction spray columns - drop formation and interfacial transfer area, Ind. Eng. Chem., 47 (2), 258-267 (1955). DOI:10.1021/ie50542a030.

[32] M. N. Sovilj, B. G. Nikolovski, M. Đ. Spasojević, Hydrodynamics of a pilot plant spray extraction column, APTEFF, 49, 159-168 (2018).

[33] M. Horvath, L. Steiner, S. Hartland, Prediction of drop diameter, hold-up and back mixing coefficients in liquid-liquid spray columns, Can. J. Chem. Eng., 56 (1), 918 (1978). DOI:10.1002/cjce.5450560102.

[34] V. L. Pebalk, B. G. Varfolomeev, K. Sh. Chigogidzeet, Hydrodynamics and mass transfer in spray extractors with closely packed drops, Khim. Prom-st. (Moscow), 8, 496 (1985).

[35] S. Samdavid, T. Renganathan, K. Krishnaiach, Hydrodynamics of a cocurrent downward liquid-liquid extraction column, $R S C A d v$., 6, 12439-12445 (2016). DOI: $10.1039 / \mathrm{C} 5 \mathrm{RA} 23649 \mathrm{E}$.

[36] J. C. Godfrey, M. J. Slater, Slip velocity relationships for liquid-liquid extraction columns, Chem. Eng. Res. Des., (Part A), 69a, 130-142 (1991).

[37] J. D. Thornton, Spray liquid-liquid extraction columns: Prediction of limiting holdup and flooding rates, Chem. Eng. Sci., 5 (5), 201-208 (1956). DOI: https://doi.org/10.1016/0009-2509(56)80031-6.

[38] B. G. Varfolomeev, V. L. Pebalk, K. Sh. Chigogidzet, N. N. Lan, R. S. Fernando, Spray extraction columns: drop size and dispersed phase holdup, Theor. Found. Chem. Eng., 34(6), 556-561 (2000). DOI: https://doi.org/10.1023/A:100522092

[39] T. Pilhofer, Hydrodynamik von tropfenschwärmen in flüssig/flüssig-sprühkolonen, Chem. Ing. Tech., 46 (18), 783, MS 133/74 (1974) (in German).

[40] A. Kumar, D. K. Vohra, S. Hartland, Sedimentation of drop dispersion in counter-current spray columns, Can. J. Chem. Eng. , 58, 154-159 (1980). DOI: $10.1002 /$ cjce. 5450580204

[41] A. Kumar, S. Hartland, Gravity settling in liquid/liquid dispersions, Can. J. Chem. Eng., 63 (3), 368-376 (1985). DOI:10.1002/cjce.5450630303

[42] A. Kumar, S. Hartland, Independent prediction of slip velocity and holdup in liquid-liquid extraction columns, Can. J. Chem. Eng., 67 (1), 17-25 (1989). DOI:10.1002/cjce.5450670104

[43] A. Kumar A., S. Hartland, Empirical prediction of operating variables. In: Liquid-Liquid Extraction Equipment, J. C. Godfrey, M. J. Slater (Eds), John Wiley \& Sons, 1994, pp. 625-735.

[44] A. Kumar, S. Hartland, A unified correlation for the prediction of dispersed phase hold-up in liquid-liquid extraction columns, Ind. Eng. Chem. Res., 34, 39253940(1995). DOI:10.1021/ie00038a032.

[45] H. C. Peterson, Effect of flow rates on holdup in a liquid-liquid extraction spray column for the system hexane-water, Ames Laboratory ISC Technical Reports. 6., Iowa State University, USA, (1950). https://lib.dr.iastate.edu/cgi/viewcontent.cgi?article $=100$ 9\&context=ameslab_iscreports, accessed July 2018. 
[46] R. Gayler, H. R. C. Pratt, Hold-up and pressure drop in packed columns, Trans. Inst. Chemical Engrs,. (London), 29, 110 (1951).

[47] R. Gayler, N. W. Roberts, H. R. C. Pratt, Liquid-liquid extraction: Part IV. A further study of hold-up in packed columns, Chem. Eng. Res. Des., 31a, 57-68 (1953).

[48] T. Sitamarayya, G. S. Laddha, Hold-up in packed liquidliquid extraction columns, Chem. Eng. Sci., 13, 263 (1960).

[49] G. Venkatamaran, G. S. Laddha, Limiting velocities, hold-up and pressure drop at flooding in packed extraction columns, Am. Inst. Chem. Engrs J., 6, 355 (1960).

[50] P. Chandrasekaran, G. S. Laddha, Counter-current twophase flow in packed liquid-liquid extraction towers estimation of hold-up at and below flooding. In: Hydraulics and Fluid Mechanics, Proceedings of the First Australasian Conference held at the University of Western Australia, 6-13th December 1962, R. Silvester (Ed.), Elsevier Ltd., 1964, pp.243-257.

DOI: https://doi.org/10.1016/C2013-0-01769-0

[51] A. Kumar, Droplet behavior in liquid/liquid extraction, $\mathrm{Ph}$ D. Thesis, ETH, Zürich, 1983.

[52] E. Barnea, J. Mizrahi, A generalized approach to the fluid dynamics of particulate systems: Part 1. General correlation for fluidization and sedimentation in solid multiparticle systems, Chem. Eng. J., 5, 171-189 (1973). DOI: https:// doi.org/10.1016/0300-9467(73)80008-5.

[53] M. Perrut, R. Loutaty, Drop size in a liquid-liquid dispersion: formation in jet break-up, Chem. Eng. J., 3, 286-293 (1972).

DOI: https://doi.org/10.1016/0300-9467(72) 85032-9.

[54] S. Vedaiyan, T. E. Degaleesan, G. S. Laddha, Mean drop size \& characteristic velocity of drop swarm in spray column, Indian J. Technol., 12, 135 (1974).

[55] A. Kumar, S. Hartland, Unified correlations for the prediction of drop size in liquid-liquid extraction columns, Ind. Eng. Chem. Res., 35, 2682-2695 (1996). DOI:10.1021/ie950674w.

[56] D. W. Marquardts, An algorithm for least-squares estimation of nonlinear parameters, J. Soc. Ind. Appl. Math., 11, 431-441 (1963). DOI:https://doi.org/101137/0111030.

[57] B. S. Chun, G. T. Wilkinson, Drop size and hold-up in countercurrent extraction with supercritical $\mathrm{CO}_{2}$ in spray column, Ind. Eng. Chem. Res., 39 (12), 4673-4677 (2000). DOI:10.1021/ie0002551.

[58] A. Salimi-Khorshidi, H. Abolghasemib,A. Khakpaya, N. Younes-Sinakia, Maximum Sauter mean diameter and terminal velocity of drops in a liquid-liquid spray extraction column, Chem. Biochem. Eng. Q., 27 (3), 279-287 (2013), https://hrcak.srce.hr/108944.

[59] S. GhaffariTooran, H. Abolghasemi, H. Bahmanyar, M. Esmaeili, A. Safari, A new correlation for overall Sherwood number in packed liquid-liquid extraction column, World Academy Sc. Eng. Tech., 55, 137-139 (2009).

[60] T. Miyauchi, T. Vermeulen, Longitudinal dispersion in two-phase continuous-flow operations, Ind. Eng. Chem. Fund., 2 (2), 113-126 (1963). DOI: $10.1021 / 1160006 \mathrm{a} 006$

[61] D. E. Hazlebeck, C. J. Geankoplis, Axial dispersion in a spray-type extraction tower, Ind.Eng. Chem. Fund., 2(4), 310-315 (1963). DOI: 10.1021/i160008a013.
[62] D. R. Brutvan, Ph.D. Thesis, Rensselaer Polytechnic Institute, Troy, New York, 1958.

[63] J. E. Henton, Back-mixing in liquid-liquid extraction spray columns. Ph.D. Thesis, University of British Columbia, Vancouver, 1967.

[64] J. E. Henton, S. D. Cavers, Continuous-phase axial dispersion in liquid-liquid spray towers, Ind. Eng. Chem. Fund., 9 (3), 384-392 (1970).

[65] M. Hozawa, H. Kono, T. Tadaki, S. Maeda, Axial dispersion in a spray type liquid-liquid extraction column, Kagaku Kogaku, 34 (5), 533-538 (1970).

[66] A. S. Zheleznyak, A. M. Landau, Calculation of longitudinal-mixing coefficients in two-phase systems with a continuous liquid phase, Theor. Fund. Chem. Eng., 7, 525 (1973).

[67] J. E. Henton, L. W. Fish, S. D. Cavers, Liquid-liquid spray towers: continuous phase Peclet numbers, Ind. Eng. Chem. Fund., 12(3), 365-372 (1973). DOI: $10.1021 / \mathrm{i} 160047 \mathrm{a} 016$.

[68] G. S. Laddha, T. R. Krishnan, S. Viswanathan, S. Vedaiyan, T. E. Degaleesan, H. E. Hoelscher, Some performance characteristics of liquid phase spray columns, AIChE J., 22 (3), 456-462 (1976). DOI:10.1002/aic.690220307.

[69] C. J. Geankoplis, J. B. Sapp, F. C. Arnold, G. Marroquin, Axial dispersion coefficients of the continuous phase in liquid-liquid spray towers, Ind. Eng. Chem. Fund., 21 (3)306-311 (1982). DOI:10.1021/i100007a019.

[70] J. S. Moon, A. Hennico, T. Vermeulen, Longitudinal dispersion in packed extraction columns with and without pulsation, Lawrence Berkley National Laboratory, University of California, USA, Report UCRL-10928, 1963. https://esholarship.org/uc/item/0bj2q2vx, accessed July 2018.

[71] K. W. McHenry, R. H. Wilhelm, Axial mixing of binary gas mixtures flowing in a random bed of spheres, AIChE J., 3 (1), 83-91 (1957). DOI: 10.1002/aic.690030115.

[72] A. Hennico, G. Jacques, T. Vermeulen, Segmented laminar flow and other models for packed-bed longitudinal dispersion, Lawrence Berkley National Laboratory, University of California, USA, Report UCRL-10696, 1964.

[73] J. M. P. Q. Delgado, A critical review of dispersion in packed beds, Heat Mass Transfer., 42 (4), 279-310 (2006). DOI:10.1007/s00231-005-0019-0.

[74] N. W. Han, J. Bhakta, R. G. Carbonell, Longitudinal and lateral dispersion in packed beds: Effect of column length and particle size distribution, AIChE J., 31 (2), 277-288 (1985), DOI: 10.1002/aic.690310215.

[75] S. F. Chung, C. Wen, Longitudinal dispersion of liquid flowing through fixed and fluidized beds, AIChE J., 14 (6), 857-866 (1968),DOI: 10.1002/aic.690140608

[76] C. L. De Ligny, Coupling between diffusion und convection in radial dispersion of matter by fluid flow through packed beds, Chem. Eng. Sci., 25 (7), 11771181 (1970). DOI: https://doi.org/10.1016/0009-2509(70)85007-2.

[77] S. O. Rastegar, T. Gu, Empirical correlations for axial dispersion coefficient and Peclet number in fixed-bed columns, J. Chromatogr. A., 1490, 133-137 (2017). DOI: org/10.1016/j.chroma.2017.02.026. 


\section{ABREVIATIONS}

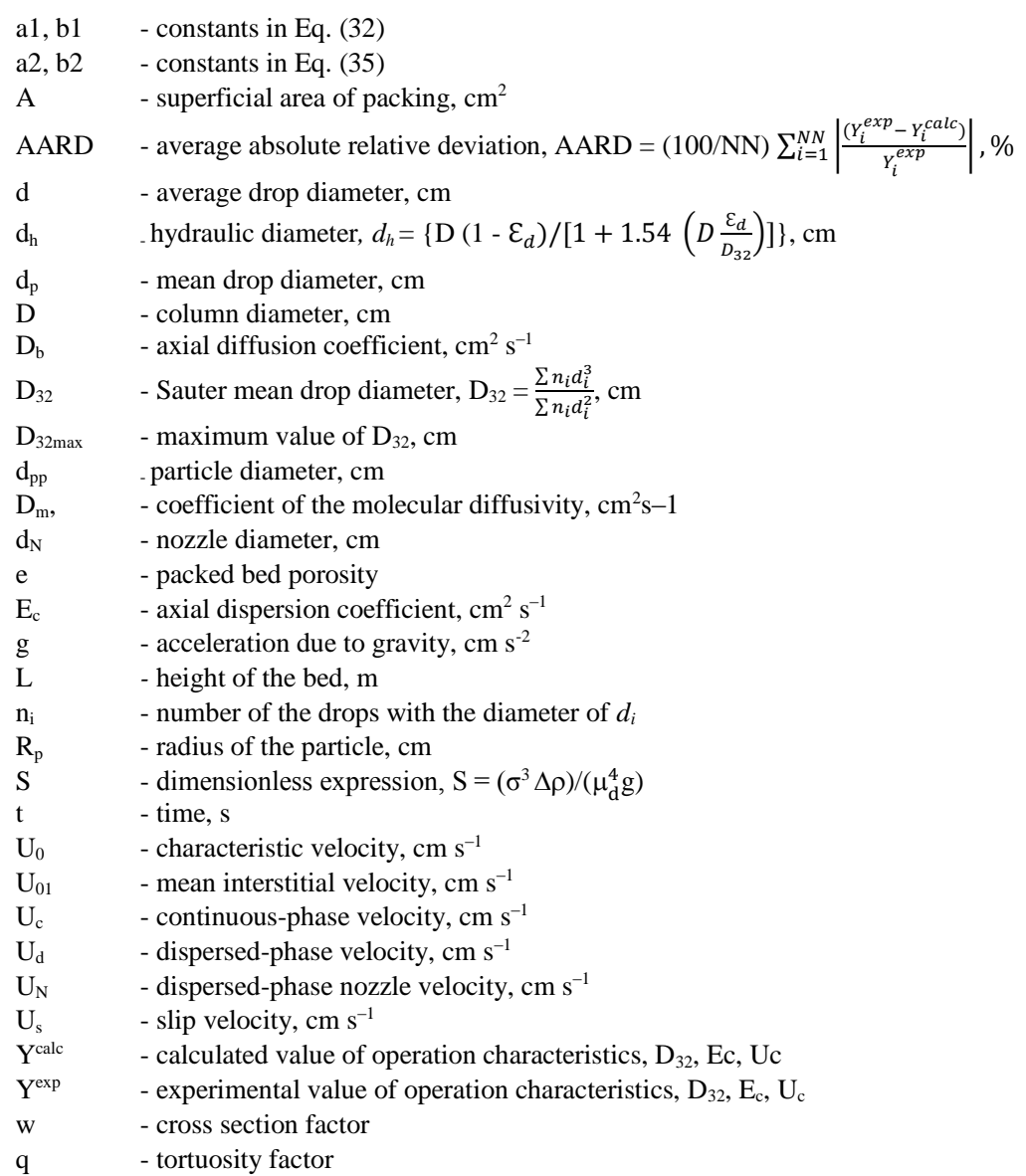

\section{Greek symbols}

$\varepsilon_{\mathrm{b}} \quad$ - bed voidage

$\varepsilon_{\mathrm{d}} \quad$ - dispersed-phase holdup

ep - porosity

$\varepsilon_{\text {st }} \quad$ - static dispersed-phase holdup

$\theta \quad$ - dimensionless time

$\mu \quad$ - relative viscosity, $\mu=\left(\mu_{\mathrm{c}}+\mu_{\mathrm{d}}\right) /\left(0.667 \mu_{\mathrm{c}}+\mu_{\mathrm{d}}\right)$

$\mu_{\mathrm{c}} \quad$ - continuous-phase dynamic viscosity, $\mathrm{g} \mathrm{cm}^{-1} \mathrm{~s}^{-1}$

$\mu_{\mathrm{d}} \quad$ - dispersed-phase dynamic viscosity, $\mathrm{g} \mathrm{cm}^{-1} \mathrm{~s}^{-1}$

$\mu_{\mathrm{f}} \quad$ - dynamic viscosity of liquid phase, Pa s

$v_{\mathrm{c}} \quad$ - continuous-phase kinematic viscosity, $\mathrm{cm} \mathrm{s}^{-2}$

$\Delta \rho \quad-$ density difference between phases, $\Delta \rho=\rho_{\mathrm{c}}-\rho_{\mathrm{d}}, \mathrm{g} \mathrm{cm}^{-3}$

$\rho_{\mathrm{c}} \quad$ - continuous-phase density, $\mathrm{g} \mathrm{cm}^{-3}$

$\rho_{\mathrm{d}} \quad$ - dispersed-phase density $\mathrm{g} \mathrm{cm}^{-3}$

$\rho_{\mathrm{f}} \quad-$ density of liquid phase, $\mathrm{g} \mathrm{m}^{-3}$

$\sigma \quad-$ interfacial tension, $\mathrm{g} \mathrm{s}^{-2}$

\section{Dimensionless numbers}

Ar - Archimedes number, $\operatorname{Ar}=\left(\Delta \rho \operatorname{gd}^{3} \rho_{\mathrm{c}}\right) / \mu_{\mathrm{c}}{ }^{2}$

Eö - Eötvös number, Eö $=\left(\mathrm{d}_{\mathrm{N}}^{2} \mathrm{~g} \Delta \rho\right) / \sigma$

Eö - Eötvös number based on the Sauter mean drop diameter, Eö $\ddot{d}_{\mathrm{d}}=\left(D_{32}^{2} g \Delta \rho\right) / \sigma$,

$\mathrm{Pe}_{\mathrm{p}} \quad$ - Peclet number based on the particle diameter, $\mathrm{Pe} \mathrm{p}_{\mathrm{p}}=\left(\mathrm{U}_{\mathrm{it}} \mathrm{d}_{\mathrm{pp}}\right) / \mathrm{D}_{\mathrm{b}}$

$\mathrm{Pe}_{\mathrm{m}} \quad$ - Peclet number based on the molecular diffusivity, $\mathrm{Pe}=\left(\mathrm{U}_{01} L\right) / D_{m}$

$\operatorname{Re} \quad-$ Reynolds number, $\operatorname{Re}=\left(\mathrm{U}_{\mathrm{s}} \mathrm{d} \rho_{\mathrm{c}}\right) / \mu_{\mathrm{c}}$

$\mathrm{Re}_{\mathrm{it}} \quad$ - Reynolds number based on interstitial velocity, $\mathrm{Re}_{\mathrm{it}}=\left(2 \mathrm{R}_{\mathrm{p}} \mathrm{U}_{\mathrm{it}} \varepsilon_{\mathrm{b}} \rho_{\mathrm{f}}\right) / \mu_{\mathrm{f}}$

$\operatorname{Re}_{N} \quad-$ Reynolds number based on the nozzle diameter, $R e_{N}=\left(U_{N} d_{N} \rho_{d}\right) / \mu_{d}$

$\operatorname{Re}_{\mathrm{c}} \quad-$ Reynolds number based on the continuous phase, $\operatorname{Re}_{\mathrm{c}}=\left(\mathrm{U}_{\mathrm{N}} \mathrm{d}_{\mathrm{N}} \rho_{\mathrm{c}}\right) / \mu_{\mathrm{c}}$

$\operatorname{Re}_{\mathrm{d}} \quad-$ Reynolds number based on the dispersed phase, $\operatorname{Re}_{\mathrm{d}}=\left(\mathrm{U}_{\mathrm{s}} \mathrm{d}_{\mathrm{N}} \rho_{\mathrm{d}}\right) / \mu_{\mathrm{d}}$.

$\operatorname{Re}_{\mathrm{k}} \quad-$ Reynolds number based on the molecular diffusivity, $\operatorname{Re}_{\mathrm{k}}=\left(\mathrm{U}_{\mathrm{it}} \mathrm{d}_{\mathrm{pp}} \rho_{\mathrm{c}}\right) / \mu_{\mathrm{c}}$.

Sc - Schmidt number, Sc $=\mu_{\mathrm{s}} /\left(\rho_{\mathrm{s}} \mathrm{D}_{\mathrm{m}}\right)$

We - Weber number, We $=\left(U_{N}^{2} d_{N} \Delta \rho\right) / \sigma$

$\mathrm{We}_{\mathrm{c}} \quad-$ Weber number based on the nozzle velocity, $\mathrm{We}_{\mathrm{c}}=\left(\mathrm{U}_{\mathrm{N}}^{2} \mathrm{~d}_{\mathrm{N}} \rho_{\mathrm{c}}\right) / \sigma$

$\mathrm{We}_{\mathrm{d}} \quad-$ Weber number based on the dispersed phase, $W e_{d}=\left(U_{N}^{2} d_{N} \rho_{d}\right) / \sigma$ 